\title{
Pneumonia severity index in the immunocompromised
}

\author{
Kevin M Sanders MD FRCPC, Theodore K Marras MD FRCPC, Charles KN Chan MD FRCPC FCCP FACP
}

\begin{abstract}
KM Sanders, TK Marras, CKN Chan. Pneumonia severity index in the immunocompromised. Can Respir J 2006;13(2):89-93.
\end{abstract}

BACKGROUND: The pneumonia severity index (PSI) accounts for many comorbidities, but not immunosuppression.

OBJECTIVES: To document the utility of the PSI to predict mortality in immunocompromised patients (IP) with communityacquired pneumonia (CAP).

METHODS: Charts of 284 patients with immunosuppression and CAP were reviewed, and these patients were compared with a contemporary sample of non-IP with CAP. The ability of the PSI to predict mortality was assessed by using multiple logistic regression. Discrimination of the PSI was studied by using the concordance index. RESULTS: Thirty-nine of 284 IP died. Mortality varied according to the etiology of the immunosuppression. Patients with HIV, solid organ transplantation or treatment with immunosuppressive drugs $(n=118)$ had a low in-hospital mortality $(4.3 \%)$ and were classified as low risk. IP with hematological malignancies, chemotherapy, chest radiation or marrow transplantation $(n=166)$ had a high mortality (20\%) and were classified as high risk. Compared with non-IP, lowrisk IP had similar PSI-controlled mortality $(\mathrm{OR}=0.9, \mathrm{P}=0.80)$, whereas high-risk IP had significantly greater mortality $(\mathrm{OR}=2.8$, $\mathrm{P}<0.0001)$. The concordance index revealed similar discrimination for the PSI in low-risk IP (0.77) and in non-IP (0.7), but inferior discrimination in high-risk patients (0.6).

CONCLUSIONS: Patients with CAP and immunosuppression can be divided into low-risk and high-risk groups. The low-risk IP have mortality similar to non-IP and can be risk stratified by using the PSI.

Key Words: Community-acquired infections; Immunocompromised host; Pneumonia; Severity of illness index

\section{Indice de gravité de la pneumonie chez des sujets immunodéprimés}

HISTORIQUE : L'indice de gravité de la pneumonie (IGP) peut expliquer de nombreuses comorbidités, mais non l'immunosuppression. OBJECTIFS : Documenter l'utilité de l'IGP à prédire la mortalité chez des sujets immunodéprimés atteints d'une pneumonie extrahospitalière ( $\mathrm{PEH})$. MÉTHODES : Les dossiers de 284 patients immunodéprimés atteints d'une PEH ont été passés en revue et ces patients ont été comparés à un échantillon contemporain de sujets atteints de PEH non immunodéprimés. La valeur prédictive de l'IGP en regard de la mortalité a été évaluée par analyse de régression logistique multiple. Le seuil de mobilité de l'IGP a été étudié à l'aide de l'indice de concordance.

RÉSULTATS : Trente-neuf des patients immunodéprimés sur 284 sont décédés. La mortalité variait selon l'étiologie de l'immunosuppression. La présence du VIH, la greffe d'un organe plein ou le traitement immunosuppresseur $(\mathrm{n}=118)$ ont donné lieu à un faible taux de mortalité durant l'hospitalisation $(4,3 \%)$ et on leur a assigné une catégorie de risque faible. L'immunosuppression associée aux cancers du sang, à la chimiothérapie, à la radiothérapie thoracique ou à la transplantation de moelle osseuse $(\mathrm{n}=166)$ ont pour leur part donné lieu à un taux de mortalité élevé (20\%) et on leur a assigné une catégorie de risque élevé. Comparativement aux sujets non immunodéprimés, les sujets exposés à un risque faible présentaient le même taux de mortalité selon l'IGP ( $R R=0,9, p=0,80$ ), alors que les sujets à haut risque présentaient un taux de mortalité beaucoup plus élevé $(R R=2,8, p<0,0001)$. L'indice de concordance a révélé un seuil de mobilité similaire pour l'IGP chez les sujets immunodéprimés à risque faible $(0,77)$ et chez les sujets non immunodéprimés $(0,7)$, mais un seuil de mobilité plus faible pour les sujets à risque élevé $(0,6)$.

CONCLUSIONS : Les patients immunodéprimés qui souffrent d'une PEH peuvent être subdivisés en deux groupes selon qu'ils sont exposés à un risque faible ou élevé. Les immunodéprimés à risque faible présentent le même taux de mortalité que les sujets non immunodéprimés et peuvent être stratifiés selon leur risque au moyen de l'IGP.
$\mathrm{C}_{\mathrm{h}}$ rommunity-acquired pneumonia (CAP) is well known to be a major cause of morbidity and mortality with a large financial burden. In the United States, a large proportion of the costs for CAP relate to the 500,000 hospitalizations annually for this disease (1-3). To manage the challenges of maintaining care quality while limiting treatment costs, many investigators have turned to the development of prognostic scores $(4,5)$. The most widely accepted is the pneumonia severity index (PSI) developed by Fine et al (4), which uses a combination of age and clinical, laboratory and radiographic features to estimate the mortality for an episode of CAP. Recent guidelines have recommended the PSI as a prognostic tool and as a resource for guiding admission decisions (6-8). These guidelines, however, do not include immunocompromised patients (IP), and although the PSI included IP in its validation (9), it currently is not being applied to this patient population $(7,8)$.

Because more patients admitted with CAP are immunosuppressed, it is imperative to have appropriate prognostic tools for these patients (10). A recent study of patients admitted to hospital for CAP showed that 57\% were immunocompromised (10). Although prognostic tools have been developed, these apply only to certain subgroups of IP $(11,12)$. To date, there is no proven prognostic score that can be used for a broad range of IP with CAP. Because IP were included in the development of the PSI, we hypothesized that the PSI would also be useful in these patients. In addition, we speculated that additional factors, especially those reflecting the nature of immune suppression, are important in predicting mortality in IP admitted to hospital with CAP. Therefore, our objectives were to study 
the prognostic utility of the PSI in IP admitted to hospital with CAP and to identify other important predictors of mortality in this patient population.

\section{Study site and patients}

\section{METHODS}

The present retrospective cohort study was performed by reviewing charts of patients admitted with CAP to three tertiary care teaching hospitals and one cancer care hospital between October 1998 and June 2000. The research ethics boards of the University Health Network and Mount Sinai Hospital, Toronto, Ontario, approved the study. Charts were identified for review by using the International Classification of Diseases, Ninth Revision (13) codes for respiratory diseases. At the cancer care centre, charts were also identified by reviewing cancer registries for admissions with pneumonia. All identified patients had their charts screened for eligibility by one of the investigators (KMS).

Patients satisfying the criteria for both CAP and for being immunocompromised were included in the study. CAP was defined as at least one symptom suggestive of pneumonia (ie, dyspnea, cough, fever or purulent sputum production), with accompanying radiographic evidence compatible with pneumonia. In addition, patients required a working diagnosis of pneumonia and must have received antibiotics within the first $48 \mathrm{~h}$ after admission. Patients were considered immunocompromised if they had any of the following: HIV infection, regardless of $\mathrm{CD}^{+}$lymphocyte count; a diagnosis of hematological malignancy; a solid organ transplantation; a bone marrow transplantation within one year of admission, or at any time following bone marrow transplantation for those with graft versus host disease; immunosuppressive drug use (ie, corticosteroid use greater than $15 \mathrm{mg} /$ day prednisone [or the equivalent] for more than 21 days within three months of admission [10,14,15], cyclosporine or azathioprine use within three months of admission, and methotrexate use greater than $12.5 \mathrm{mg} /$ week within three months of admission [16]); cytotoxic chemotherapy within six months of admission (17); chest radiation therapy within one month of admission (18); and hypogammaglobulinemia including functional or structural hyposplenism (19).

Patients were excluded from analysis if they had known or suspected tuberculosis, cystic fibrosis, known postobstructive pneumonia, or a concurrent nonrespiratory infection requiring antibacterial therapy. Patients were also excluded if discharged from an acute care hospital within seven days of symptom onset. Patients admitted to hospital with a diagnosis of CAP more than once during the study period had each episode included as an independent event. Non-IP comprised a group of nonimmunosuppressed patients with CAP admitted to hospital over the same period. Data on these patients have been reported previously (20).

\section{Data collection}

A trained health records reviewer collected data from eligible charts. Data of interest included demographic and clinical information required to calculate the PSI. Data from the first available physical examination were used to calculate the PSI; these data were recorded on presentation to the emergency department, before any resuscitation by emergency room staff. Similarly, the first available laboratory values were used for the PSI calculation. If no values were recorded in the first $24 \mathrm{~h}$ of presentation, then that laboratory value was assumed to be normal.

The primary outcome recorded was in-hospital mortality, with the cause of death recorded from the death certificate, or autopsy data when available. Factors included in the PSI, etiology of immunosuppression, absolute neutrophil count, time to antibiotics, the presence of bilateral opacities on chest radiograph and total white blood cell count were also recorded.

Information from medical records (charts and electronic patient records) was entered directly into an electronic database, designed in Microsoft Access (Microsoft Corporation, USA). One of the investigators periodically reviewed the entire database for inconsistencies and, when identified, they were investigated and corrected by a repeated review of the medical records.

\section{Statistical analysis}

All data were statistically analyzed with SAS version 8.0 (SAS Institute, USA) and Epi Info version 6 (Centers for Disease Control and Prevention, USA). Descriptive statistics of baseline patient data were examined. Continuous data were expressed either as a mean $\pm \mathrm{SD}$ or median (quartiles), depending on the distribution, and were compared by $t$ tests or Mann-Whitney $U$ tests as appropriate. Baseline categorical data were compared by the $\chi^{2}$ test or Fisher's exact tests (Yates-corrected) as appropriate.

The predictive accuracy of the PSI was tested in two ways. Discrimination of the PSI was assessed by using the concordance index (c-index). The c-index estimates the probability that of two randomly chosen patients with discordant outcomes (one who survived and one who died), the one with the higher PSI risk class will be more likely to die. A c-index of 0.5 means that the test (PSI) is no better than chance alone, whereas a value of 1 indicates that the PSI always discriminates accurately. The c-index values for different groups were compared according to the method of Hanley and McNeil (21). Reliability (the amount of agreement between predicted and observed outcomes) was assessed by visual inspection of graphs of observed versus expected mortality and $\chi^{2}$ goodness-of-fit tests. Contingency table cells for goodness-of-fit tests were defined by PSI risk class, and classes were combined when expected values were too low to calculate a $\chi^{2}$ value.

Factors were studied for associations with mortality in bivariate followed by multivariate analyses (multiple logistic regression modelling always including the PSI score as an independent [predictor] variable). In the search for other potentially predictive variables, variables that were typically not available at the time of presentation (bacteremia and opportunistic infection) were also included. To minimize overfitting, full, prespecified models (no selection criteria, containing all variables of interest) were fitted (22).

\section{RESULTS}

A total of 284 IP were included and they were compared with 695 non-IP. Therefore, a total of 979 patients were considered in the development of the logistic models of survival. Data on the 695 non-IP have been previously reported (20).

\section{Clinical features of IP}

Baseline demographic data are presented in Table 1. Underlying causes of immunosuppression are presented in Table 2. IP were more likely than non-IP to have chronic renal failure $(22 \%$ versus $6 \%, \mathrm{P}<0.0001)$, liver disease $(7 \%$ versus $4 \%, \mathrm{P}=0.04)$ and neoplastic disease $(63 \%$ versus $16 \%$, $\mathrm{P}<0.0001)$. Congestive heart failure was more common in non-IP (32\% versus $14 \%, \mathrm{P}<0.0001)$, as was a history of stroke (19\% versus $3 \%, \mathrm{P}<0.0001)$ (Table 1$)$. IP had a severely deranged body temperature (less than $35^{\circ} \mathrm{C}$ or greater than $\left.40^{\circ} \mathrm{C}\right)$ more often than non-IP $(15 \%$ versus $3 \%, \mathrm{P}<0.0001)$. 
TABLE 1

Baseline characteristics by immune status

\begin{tabular}{lccc}
\hline & Non-IP & IP & $\mathbf{P}^{*}$ \\
\hline $\mathrm{n}$ & 695 & 284 & - \\
Age, mean years \pm SD & $76 \pm 13$ & $57 \pm 17$ & $<0.0001$ \\
Female, \% & 39 & 37 & 0.74 \\
Long-term care residence, \% & 22 & 2 & $<0.0001$ \\
ICU admission, \% & 8 & 10 & 0.45 \\
PSI, mean \pm SD & $116 \pm 37$ & $102 \pm 38$ & $<0.0001$ \\
PSI class, \% & & & $<0.0001$ \\
1 & 1 & 6 & \\
2 & 8 & 15 & \\
3 & 17 & 19 & \\
4 & 43 & 39 & \\
5 & 31 & 21 & \\
Comorbidities, $\mathrm{n}$ (\%) & & & \\
Diabetes & $132(19)$ & $43(15)$ & 0.15 \\
Chronic renal failure & $42(6)$ & $62(22)$ & $<0.0001$ \\
Liver disease & $27(4)$ & $20(7)$ & 0.04 \\
Congestive heart failure & $220(32)$ & $39(14)$ & $<0.0001$ \\
Cerebrovascular accident & $133(19)$ & $9(3)$ & $<0.0001$ \\
Neoplastic disease & $109(16)$ & $180(63)$ & $<0.0001$ \\
\hline
\end{tabular}

*Immunocompromised patients (IP) versus non-IP. ICU Intensive care unit; PSI Pneumonia severity index

However, compared with non-IP, IP had less frequent mental status changes $(12 \%$ versus $26 \%, \mathrm{P}<0.0001)$, tachypnea $(18 \%$ versus $33 \%, \mathrm{P}<0.0001)$, elevated blood glucose $(9 \%$ versus $5 \%, \mathrm{P}=0.03$ ) and hypoxia ( $46 \%$ versus $30 \%, \mathrm{P}<0.0001$ ). More IP than non-IP were anemic (ie, had a hematocrit less than $30 \%$ ) (37\% versus 5\%, $\mathrm{P}<0.0001)$.

\section{Outcomes}

CAP was defined as any pneumonia arising in the community regardless of etiology. In only $21 \mathrm{IP}$ was the etiology found to be an opportunistic infection, which was defined as any noncandidal fungal infection, Pneumocystis jiroveci pneumonia, an opportunistic virus or nontuberculous mycobacteria. There were seven cases each of viral pneumonia and $P$ jiroveci pneumonia, six fungal infections and one nontuberculous mycobacteria. One patient had two opportunistic infections, cytomegalovirus and Nocardia. Community-acquired pathogens were identified in another 67 patients. No pathogen was identified in the remaining 196 patients.

Thirty-nine of 284 IP (14\%) died. Twenty-seven (68\%) deaths were judged to be due to pneumonia, two (5\%) due to neoplastic disease and one $(2.5 \%)$ each due to pulmonary embolism, cerebral hemorrhage, gastrointestinal bleeding and arrhythmia. For six patients, no appropriate cause of death could be determined from the medical record. The median length of hospital stay was eight days in both groups.

\section{Classification of IP}

Mortality rates were observed to vary according to the etiology of immunosuppression. Patients with HIV, solid organ transplantation or treatment with immunosuppressive drugs were classified as low risk. High-risk IP had hematological malignancies, chemotherapy, chest radiation or marrow transplantation (Table 3). The mortality was far greater in high-risk IP (20\%) than in low-risk IP (4\%). In multiple logistic regression
TABLE 2

Features of immunosuppression in immunocompromised patients with pneumonia

\begin{tabular}{lc}
\hline Condition & $\mathbf{n}(\%)$ \\
\hline HIV & $37(13)$ \\
CD4+ lymphocyte count & \\
$<50$ & $16(6)$ \\
$51-100$ & $3(1)$ \\
$101-200$ & $9(3)$ \\
$201-500$ & $4(1)$ \\
$>500$ & $5(2)$ \\
Solid organ transplantation & $43(15)$ \\
Lung & $13(5)$ \\
Liver & $6(2)$ \\
Kidney & $12(4)$ \\
Heart & $8(3)$ \\
Heart-lung & $1(0.3)$ \\
Kidney-pancreas & $3(1)$ \\
Immune suppressive drug therapy* & $38(15)$ \\
Hematological malignancy & $68(24)$ \\
Acute myeloid leukemia & $12(4)$ \\
Acute lymphoblastic leukemia & $1(0.3)$ \\
Chronic myelogenous leukemia & $4(2)$ \\
Chronic lymphocytic leukemia & $13(5)$ \\
Multiple myeloma & $14(5)$ \\
Hairy cell leukemia & $2(1)$ \\
Hodgkin lymphoma & $3(1)$ \\
Non-Hodgkin lymphoma & $14(5)$ \\
Chemotherapy & $55(19)$ \\
Marrow or stem cell transplantation $\ddagger$ & $36(13)$ \\
Chest radiation therapy§ & $7(2)$ \\
\hline
\end{tabular}

*Within three months of azathioprine, cyclophosphamide, methotrexate, cyclosporine or prednisone $15 \mathrm{mg} /$ day (or equivalent) for 21 days; 'Within six months of chemotherapy; $¥$ Within one year of transplantation, or ongoing graft versus host disease; §Thoracic radiation within the past month

modelling controlled for PSI score, low-risk IP (nonmalignant IP) were not found to have statistically different mortality rates than that of non-IP $(\mathrm{OR}=0.88, \mathrm{P}=0.80)$. However, high-risk patients (malignant IP) had higher mortality rates than that of non-IP $(\mathrm{OR}=2.8, \mathrm{P}<0.0001)$.

Utility of the PSI in immunosuppressed patients Mortality increased with higher PSI class in all patient groups (Figure 1). The c-index for the PSI was 0.72 (95\% CI 0.67 to $0.78)$ for non-IP and 0.70 (95\% CI 0.60 to 0.79$)$ for all IP considered together. In comparing the different groups of IP, the c-index revealed a good discriminatory ability for the PSI in low-risk patients $(0.77$ [95\% CI 0.52 to 1.0]), but worse discrimination in high-risk patients, for whom the c-index was substantially lower (0.60 [95\% CI 0.46 to 0.74]).

Regarding reliability, Figure 1 suggests that low-risk IP have similar mortality to non-IP, whereas high-risk IP diverge more from expected mortality rates according to the PSI. $\chi^{2}$ goodnessof-fit testing suggested no statistically significant difference between observed and predicted rates of mortality when using the PSI in low-risk IP ( $\mathrm{P}=0.19)$.

Other factors affecting mortality

Other factors associated with mortality in the high-risk IP were studied. In bivariate analyses, bacteremia, white blood cell 


\section{TABLE 3}

Groups of immunosuppression in patients with pneumonia

\begin{tabular}{ll}
\hline Group & Characteristics \\
\hline Non-IP & No immunosuppression \\
Low risk & HIV \\
& Solid organ transplantation \\
& Immune medication \\
High risk & Marrow transplantation \\
& Hematological malignancies \\
& Postchemotherapy \\
& Radiation to thorax \\
\hline
\end{tabular}

Non-IP Nonimmunocompromised patients

count, neutrophil count, bilateral chest $\mathrm{x}$-ray involvement and time to antibiotics were not statistically significant predictors of mortality. Patients with opportunistic infection had a higher mortality rate ( $58 \%$ versus $18 \%, \mathrm{P}=0.003)$. The multivariable analysis comprised multiple logistic regression, employing all of the above variables, except neutrophil count, which was highly correlated with leukocyte count $(r=0.59$, $\mathrm{P}<0.0001$ ) but less informative and, therefore, removed. Only PSI score (OR for death per 10-point increase was 1.2 [95\% CI 1.01 to 1.34$], \mathrm{P}=0.03$ ) and opportunistic infection (OR for death was 7.1 [95\% CI 1.9 to 28.4], $\mathrm{P}=0.004$ ) were statistically significant predictors of mortality.

\section{DISCUSSION}

IP comprise diverse groups, each with different abilities to respond to infections. Traditionally, these patients have been excluded from guidelines for CAP because they are predisposed to different infections and presumably react differently when acquiring such infections (6-8). Thus, clinical tools such as the PSI may be widely accepted for use in non-IP, but are generally not recognized for use in IP.

Our study highlights several important observations. First, we note that IP could easily be divided into two groups based on the etiology of their immunosuppression. We use the presence of a malignancy as the source of immunosuppression to classify patients as high risk (mortality of 20\%) or low risk (mortality of $4 \%$ ). This is based on previous studies showing that IP with cancer have higher mortality rates than those in all other IP $(23,24)$. Indeed, in HIV patients, the in-hospital mortality has been found to be similar to that in non-IP $(10,25)$. Similarly, in cardiac transplant patients, CAP has been shown to have an excellent prognosis (26). This finding is in contrast to a $60 \%$ to $75 \%$ mortality rate in CAP patients with hematological malignancies $(27,28)$, and a $40 \%$ to $50 \%$ mortality rate in bone marrow transplant patients with CAP $(29,30)$. Our study is the first to directly compare IP and to suggest that IP can be risk stratified by the presence of malignancy.

Second, we showed that the PSI appears to predict mortality in low-risk IP. It was anticipated that the PSI would be a useful predictor of mortality in IP because some IP were included in the cohorts used to derive and validate the score $(4,9)$. Both the retrospective validation and the Pneumonia Patient Outcomes Research Team (PORT) study $(4,9)$ included IP, except those who were HIV positive. However, the PSI was never recommended by the authors or by clinical guidelines for use in this population. Our study identified a group of low-risk IP with mortality rates similar to that of immunocompetent patients.

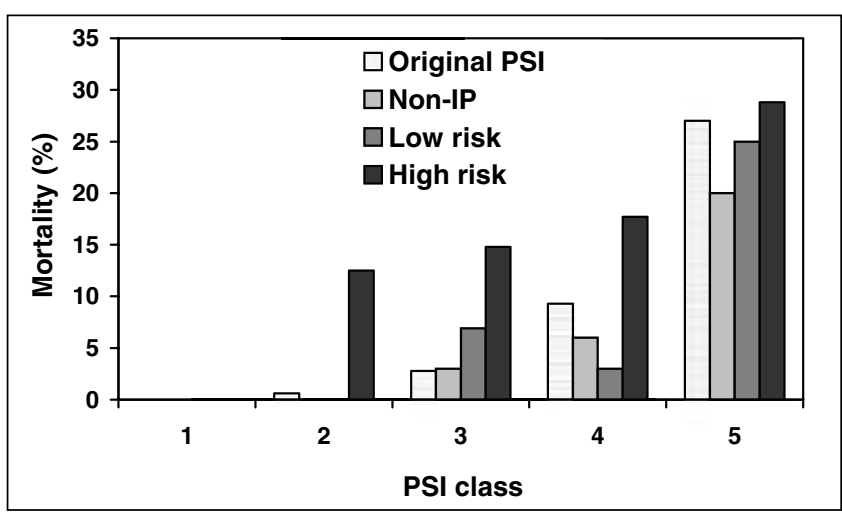

Figure 1) Mortality according to pneumonia severity index (PSI) class by immune status. Mortality in low-risk patients and nonimmunocompromised patients (non-IP) was similar, with mortality similar to the expected mortality according to PSI class (4). High-risk patients had greater mortality in each risk class. Non-IP, low risk and high risk are defined according to the definitions of the present study. Original PSI refers to the mortality observed in the validation of the PSI (4)

In this low-risk group, the PSI class predicted mortality at rates similar to that of the PORT study, suggesting that these lowrisk IP may be risk stratified in a similar fashion to non-IP.

The primary limitations of our study include its retrospective design and the relatively small sample size. Due to the retrospective nature of our study, we were unable to measure 30-day mortality (as intended with the PSI), and we were forced to rely solely on in-hospital mortality. We believe that this is reasonable because in the derivation cohort for the PSI, 30-day mortality data were also unavailable, and patients discharged from hospital before 30 days were considered alive for that analysis (4). The mortality rates in the PSI-derivation cohort (9) were essentially identical to the rates in the PSI-validation cohort (PORT study) (4). Another limitation posed by the retrospective design of the study was that some parameter values for the calculation of the PSI were missing. This is likely unimportant because the original derivation of the rule was also performed retrospectively and, similarly, made no distinction between negative and absent laboratory value criteria. Also, calculating the PSI with incomplete laboratory data is an accurate reflection of practice (ie, certain laboratory values, especially arterial blood gases, are not routinely measured). An additional limitation is the lack of comprehensive information regarding the philosophy of care. We were unable to ascertain the proportion of patients who had do not resuscitate (DNR) orders in their charts. It is possible that the mortality from pneumonia in the high-risk patients was increased compared with non-IP because DNR orders would be expected to be more common in cancer patients. We tried to limit the confounding effects of DNR orders by establishing the use of antibiotics as inclusion criteria. This would exclude patients who were 'comfort care only' from our analysis.

Our relatively small sample makes studying mortality in the lower-risk groups particularly challenging, due to the inherently lower risk of mortality and, thus, fewer outcomes. It is possible that the lack of a significant difference between low-risk patients and non-IP reflects an inadequate power to detect such a difference. Similarly, the limited sample size may also be responsible for the lack of statistical significance for some factors in predicting mortality in high-risk patients. The point 
estimates for bacteremia and bilateral chest x-ray involvement were consistent with increased mortality in both bivariate and multivariate analyses, which might have been statistically significant if the sample size had been larger.

\section{CONCLUSIONS}

A group of low-risk IP appears to be identified from the etiology of their immunosuppression. Low-risk patients have immune suppression that is not associated with malignancy and have a relatively low probability of dying from their CAP. The PSI, as originally published, appears to be effective for risk stratifying this group of patients.

ACKNOWLEDGEMENTS: We are grateful to Mr Mustafa Rawji for help in the collection of data. Dr Marras is a Canadian Institutes of Health Research and Canadian Thoracic Society postdoctoral fellow. This study was supported in part by an unrestricted educational grant from Janssen-Ortho Inc.

\section{REFERENCES}

1. Marston BJ, Plouffe JF, File TM Jr, et al; The Community-Based Pneumonia Incidence Study Group. Incidence of communityacquired pneumonia requiring hospitalization. Results of a population-based active surveillance Study in Ohio. Arch Intern Med 1997;157:1709-18.

2. Niederman MS, McCombs JS, Unger AN, Kumar A, Popovian R. The cost of treating community-acquired pneumonia. Clin Ther 1998;20:820-37.

3. Lave JR, Lin CC, Fine MJ. The cost of treating patients with community-acquired pneumonia. Semin Respir Crit Care Med 1999;20:189-98.

4. Fine MJ, Auble TE, Yealy DM, et al. A prediction rule to identify low-risk patients with community-acquired pneumonia. N Engl J Med 1997;336:243-50.

5. Ewig S, Ruiz M, Mensa J, et al. Severe community-acquired pneumonia. Assessment of severity criteria. Am J Respir Crit Care Med 1998;158:1102-8.

6. Niederman MS, Mandell LA, Anzueto A, et al; American Thoracic Society. Guidelines for the management of adults with community-acquired pneumonia. Diagnosis, assessment of severity, antimicrobial therapy, and prevention. Am J Respir Crit Care Med 2001;163:1730-54.

7. Mandell LA, Marrie TJ, Grossman RF, Chow AW, Hyland RH. Canadian guidelines for the initial management of communityacquired pneumonia: An evidence-based update by the Canadian Infectious Diseases Society and the Canadian Thoracic Society. The Canadian Community-Acquired Pneumonia Working Group. Clin Infect Dis 2000;31:383-421.

8. Bartlett JG, Dowell SF, Mandell LA, File Jr TM, Musher DM, Fine MJ. Practice guidelines for the management of community-acquired pneumonia in adults. Infectious Diseases Society of America. Clin Infect Dis 2000;31:347-82.

9. Fine MJ, Hanusa BH, Lave JR, et al. Comparison of a disease-specific and a generic severity of illness measure for patients with community-acquired pneumonia. J Gen Intern Med 1995;10:359-68.
10. Mundy LM, Auwaerter PG, Oldach D, et al. Community-acquired pneumonia: Impact of immune status. Am J Respir Crit Care Med 1995;152:1309-15.

11. Cordero E, Pachon J, Rivero A, et al; The Grupo Andaluz para el Estudio de las Enfermedades Infecciosas. Community-acquired bacterial pneumonia in human immunodeficiency virus-infected patients: Validation of severity criteria. Am J Respir Crit Care Med 2000;162:2063-8

12. Arozullah AM, Parada J, Bennett CL, et al. A rapid staging system for predicting mortality from HIV-associated community-acquired pneumonia. Chest 2003;123:1151-60.

13. International Classification of Diseases, Ninth Revision. Geneva: World Health Organization, 1979.

14. Yale SH, Limper AH. Pneumocystis carinii pneumonia in patients without acquired immunodeficiency syndrome: Associated illness and prior corticosteroid therapy. Mayo Clin Proc 1996;71:5-13.

15. Stuck AE, Minder CE, Frey FJ. Risk of infectious complications in patients taking glucocorticosteroids. Rev Infect Dis 1989;11:954-63.

16. Kanik KS, Cash JM. Does methotrexate increase the risk of infection or malignancy? Rheum Dis Clin North Am 1997;23:955-67.

17. Mackall CL, Fleisher TA, Brown MR, et al. Age, thymopoiesis, and $\mathrm{CD}^{+}$T-lymphocyte regeneration after intensive chemotherapy. N Engl J Med 1995;332:143-9

18. Uh S, Lee SM, Kim HT, et al. The effect of radiation therapy on immune function in patients with squamous cell lung carcinoma. Chest 1994;105:132-7.

19. Brigden ML, Pattullo AL. Prevention and management of overwhelming postsplenectomy infection - An update. Crit Care Med 1999;27:836-42.

20. Marras TK, Jamieson L, Chan CK. Inpatient care of communityacquired pneumonia: The effect of antimicrobial guidelines on clinical outcomes and drug costs in Canadian teaching hospitals. Can Respir J 2004;11:131-7.

21. Hanley JA, McNeil BJ. A method of comparing the areas under receiver operating characteristic curves derived from the same cases. Radiology 1983;148:839-43.

22. Steyerberg EW, Eijkemans MJ, Harrell FE Jr, Habbema JD. Prognostic modelling with logistic regression analysis: A comparison of selection and estimation methods in small data sets. Stat Med 2000;19:1059-79.

23. Hilbert G, Gruson D, Vargas F, et al. Noninvasive ventilation in immunosuppressed patients with pulmonary infiltrates, fever, and acute respiratory failure. N Engl J Med 2001;344:481-7.

24. Rano A, Agusti C, Benito N, et al. Prognostic factors of non-HIV immunocompromised patients with pulmonary infiltrates. Chest 2002;122:253-61.

25. Feldman C, Glatthaar M, Morar R, et al. Bacteremic pneumococcal pneumonia in HIV-seropositive and HIV-seronegative adults. Chest 1999;116:107-14.

26. Lenner R, Padilla ML, Teirstein AS, Gass A, Schilero GJ. Pulmonary complications in cardiac transplant recipients. Chest 2001;120:508-13.

27. Bodey GP, Rodriguez V, Chang HY, Narboni. Fever and infection in leukemic patients: A study of 494 consecutive patients. Cancer 1978;41:1610-22.

28. Hildebrand FL Jr, Rosenow EC III, Habermann TM, Tazelaar HD. Pulmonary complications of leukemia. Chest 1990;9:1233-9.

29. Whimbey E, Champlin RE, Couch RB, et al. Community respiratory virus infections among hospitalized adult bone marrow transplant recipients. Clin Infect Dis 1996;22:778-82.

30. Leung AN, Gosselin MV, Napper CH, et al. Pulmonary infections after bone marrow transplantation: Clinical and radiographic findings. Radiology 1999;210:699-710. 


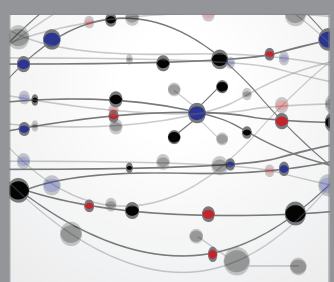

The Scientific World Journal
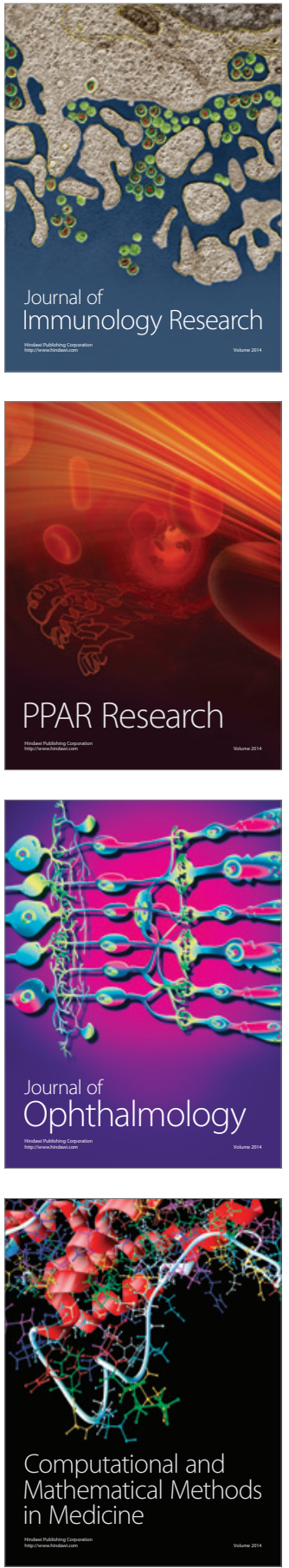

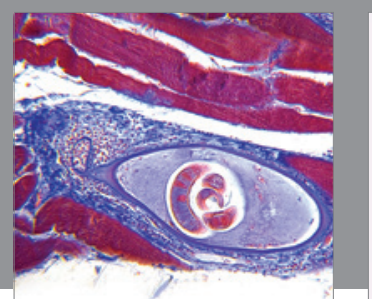

Gastroenterology Research and Practice

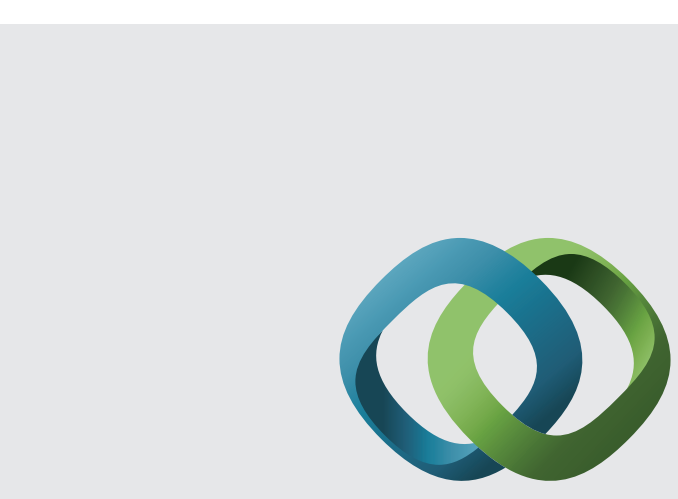

\section{Hindawi}

Submit your manuscripts at

http://www.hindawi.com
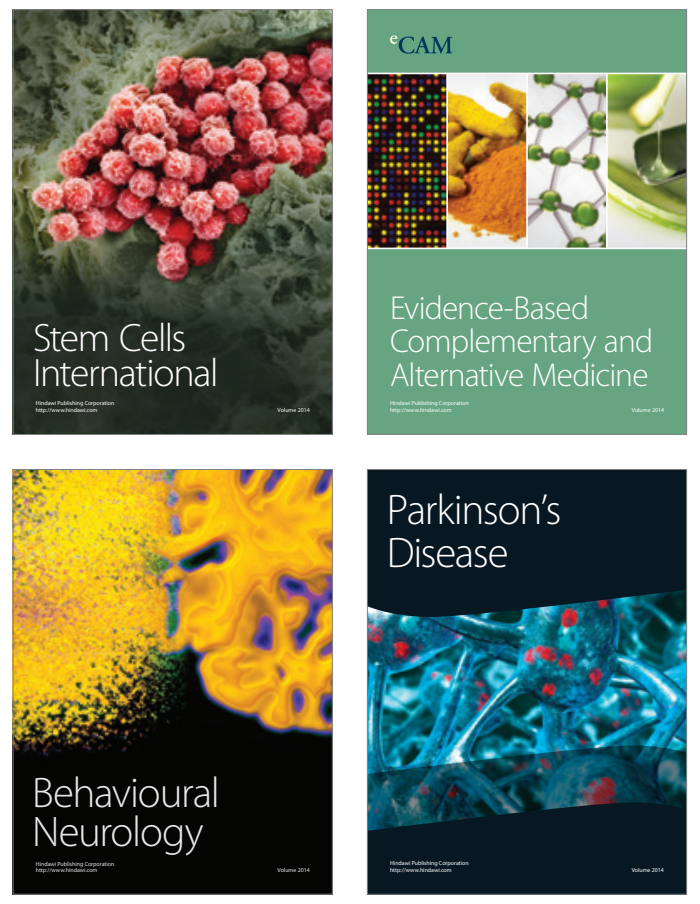
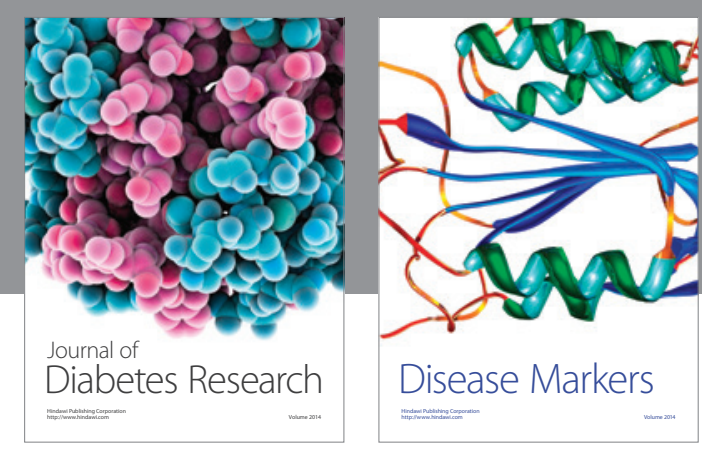

Disease Markers
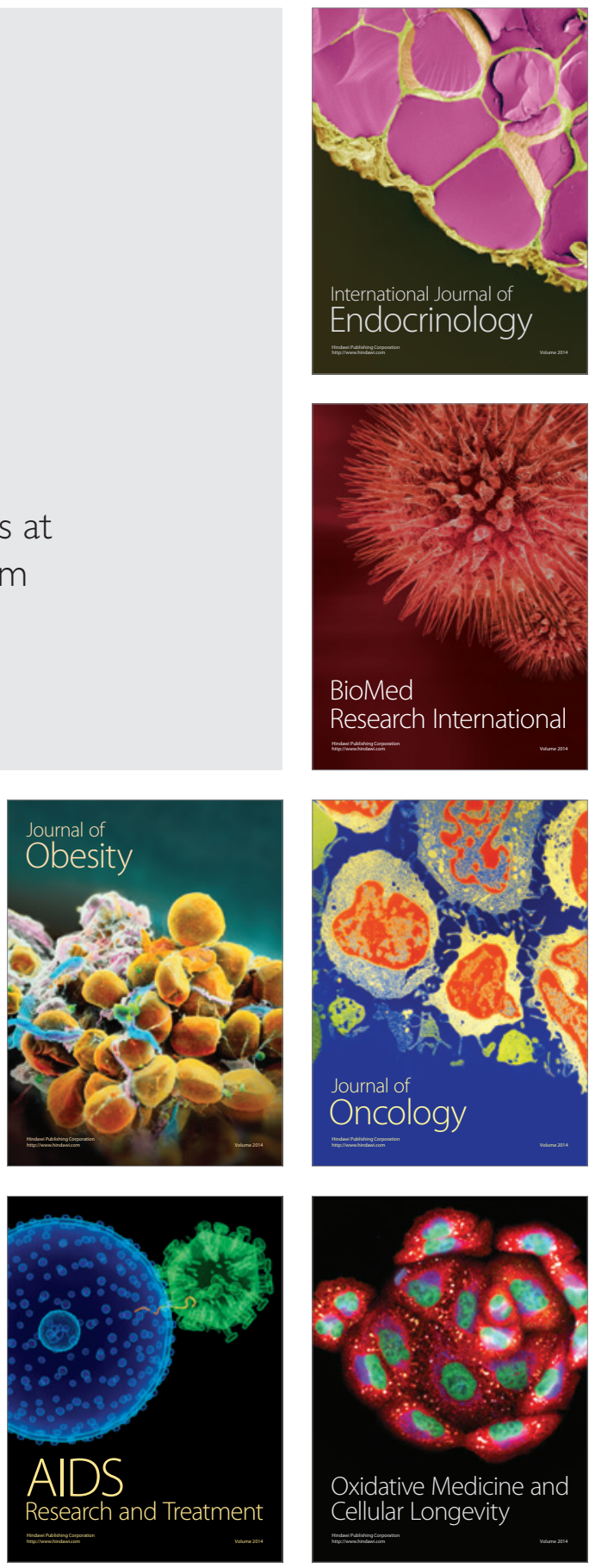